\title{
Genoveses en Lima a finales del virreinato
}

\section{Genoeses in Lima at the end of the viceroyalty}

Diego Lévano ${ }^{1}$

Pontificia Universidad Católica del Perú

\section{Resumen}

Descripción de la dinámica económica de la colonia genovesa asentada en Lima al final del periodo colonial y trata especialmente su participación en las redes comerciales locales y el comercio ultramarino. Se aportan datos sobre su estado, labores y trabajos, transacciones económicas, su participación cotidiana en los diferentes procesos históricos del Perú y su adaptación y mantenimiento de intereses en los diversos gobiernos en los que les tocó vivir. Se aborda la búsqueda de su naturalización como vecinos por parte de algunos genoveses y la presencia del comercio ligur gaditano en la plaza limeña a través de representantes y apoderados. Como co-

1 Magíster en Historia en dicha casa de estudios.

Contacto: dlevano@pucp.edu.pe 
rolario, trata el momento de la ocupación de Lima por las fuerzas patriotas y cómo esto afectó a los genoveses, ya fueran como naturalizados españoles o como extranjeros identificados con la causa realista.

Palabras clave: Genoveses, Lima, virreinato del Perú, extranjeros, emigración

\section{Abstract}

Description of the economic dynamics of the Genoese colony settled in Lima at the end of the colonial period and deals especially with their participation in local commercial networks and overseas trade. It provides data on their status, work and jobs, economic transactions, their daily participation in the different historical processes of Peru and their adaptation and maintenance of interests in the various governments in which they lived. It addresses the search for their naturalization as neighbors by some Genoeses and the presence of the Cadiz Ligurian trade in Lima through representatives and attorneys. As a corollary, it deals with the moment of the occupation of Lima by the patriotic forces and how this affected Genoeses, either as naturalized Spaniards or as foreigners identified with the realistic cause.

Key words: Genoeses, Lima, viceroyalty of Peru, foreigners, emigration

Este ensayo describe la dinámica económica de la colonia genovesa asentada en la Ciudad de Los Reyes en las postrimerías del periodo colonial y trata especialmente su participación en las redes comerciales a nivel local y su ampliación 
al comercio ultramarino. Se aportan datos sobre su estado, labores y trabajos, transacciones económicas, así como su actuación cotidiana en los diferentes procesos históricos del Perú y su adaptación y mantenimiento de intereses en relación con los diversos gobiernos en los que les tocó vivir.

La investigación tomó como inicio el proceso de expulsión de extranjeros en Lima en la década de 1760 hasta años después del proceso independentista. Se exploran dos temas: la búsqueda de su naturalización como vecinos por parte de algunos genoveses y la presencia del comercio ligur gaditano en la plaza limeña a través de representantes y apoderados. Como corolario, aborda el momento de la ocupación de Lima y cómo esto afectó a los genoveses, ya fuera como naturalizados españoles o como extranjeros identificados con la causa realista.

Recurrentes son las referencias a la presencia genovesa en Lima en el siglo XVI y comienzos del XVII. En el siglo XVIII, su presencia cobró mayor visibilidad a partir del proceso de expulsión de extranjeros ejecutado entre 1763 y $1773 .^{2}$ Las formas más comunes de arribo a la capital peruana fueron como polizontes o miembros de la tripulación de barcos que desembarcaban en el Callao, siempre acompañando o portando mercancías. Por ejemplo, en 1765 el navío San Juan Bautista, alias El Toscano, traía como tripulación a los genoveses Tomás Carminati, mayordomo; al primer repostero Andrés de Torres; los cocineros de cámara Nicolás Braco y Juan Bautista Colombini (Columbino); y a los cocineros de

2 La expulsión de extranjeros en 1767 ha sido estudiada por Scarlett O'Phelan para el caso de los irlandeses en el texto "Una doble inserción. Los irlandeses bajo los Borbones: del puerto de Cádiz al Perú” (2005). 
tripulación Antonio Roso y Matheo Peilo. ${ }^{3}$ Tanto Colombino como Roso tendrán luego un historial comercial en la ciudad, en la que realizaban compras y vendían mercancías. Otro caso es el de Juan Bautista Pelufo (Belufo), cocinero de cámara del navío La Limeña, cuyas transacciones comerciales se pueden seguir en el ajuste de cuentas por su fallecimiento. ${ }^{4} \mathrm{Al}$ parecer, Pelufo llegó a la ciudad de Lima a inicios de la década de 1780 y se dedicó a la administración de una pulpería. ${ }^{5}$

Esta forma de inserción en territorio americano es confirmada por Catia Brilli para el Río de la Plata (2011, p. 939), quien refiere que las primeras oleadas migratorias de ligures hacia América eran de exploración y fueron realizadas en muchos casos por personajes anónimos asentados en la península que buscaban oportunidades en el comercio transatlántico. Entre estos, algunos muy jóvenes buscaban fortuna, mientras que otros venían como comisionados de algún mercader y portando encargos, es decir, viendo la posibilidad de entablar relaciones comerciales con negociantes locales americanos. En su mayoría, quienes llegaron tenían experiencias comerciales en otros territorios de la monarquía.

Del rápido censo levantado en 1775 , a raíz de la real cédula de expulsión de extranjeros, se identificaron en Lima a 58

3 Archivo General de Indias (en adelante AGI), Contratación, 5650, N 1; 1765. No se sabe a ciencia cierta lo rentable que podía ser este trabajo en los barcos, pero en el inventario de los bienes de Juan Bautista Colombini, fallecido en el hospital de San Andrés (Lima), se encontraron 1,460 pesos líquidos.

4 AGI, Contratación, 5703, N 12; 1787.

5 Archivo General de la Nación (en adelante AGN), Cabildo, CA-JO.1, Leg. 104, Exp. 1662; 1783. 
residentes extranjeros (Campbell, 1972, pp. 153-163). De los cuales, el $34.5 \%$ fueron identificados como genoveses. En esos años, en Cádiz, la población genovesa representaba el 50\% de extranjeros (Bustos Rodríguez, 2005, p. 109). Treinta ańos más tarde, en un censo de Lima de 1813, se consignaron 106 extranjeros en sus 6 parroquias, es decir, un $0.19 \%$ del total de la población (incluidos religiosos y esclavos). ${ }^{6}$ Solo en la catedral, los extranjeros (98) representaban el $0.50 \%$ de censados. ${ }^{7} \mathrm{Y}$ de la población extranjera de esta parroquia, los genoveses representaban el 23\%. Aunque el número de genoveses identificados en el periodo 1760 1830 fueron más de 180, dentro del grupo de españoles había algunos genoveses que no declaraban su verdadero origen o se consideraban naturalizados, además de los transeúntes.

\section{Ligures peninsulares y sus contactos con el comercio limeño}

Los genoveses residentes en Cádiz vieron a Lima como una plaza importante para sus negocios, dado que a través de representantes comerciantes particulares y de casas de comercio no estaban ajenos al movimiento económico limeño. Recordemos que en el conglomerado de extranjeros asentados en el puerto gaditano había dos grupos mayoritarios: genoveses y franceses. Siguiendo las referencias de Bustos Rodríguez, en el padrón de Cádiz de 1713, los genoveses representaban el $42 \%$ de extranjeros y el $50 \%$ entre 1773 y 1791 , porcentaje que alcanzó el 57.5\% en 1801 (2005, pp. 106-122). Brilli confirma la importancia comercial ligur en Cádiz e indica

6 AGN, Colección Moreyra, Leg. 45, Doc. 1335. 1813

7 Archivo Arzobispal de Lima (en adelante AAL), Censo de la Parroquia Catedral. Lima 1813 
que en 1771 los genoveses constituían el tercer grupo por número de casas comerciales al por mayor; y en 1788 existían al menos 60 bodegas de minoristas originarios de Génova (2010, p. 87). En general, las relaciones diplomáticas entre la República de Génova y la monarquía española favorecían el flujo migratorio, a ello se sumaba la predisposición de los genoveses al comercio marino, que convertía a Cádiz en una plaza apreciada.

Los comerciantes genoveses buscaban condiciones favorables para el desarrollo de sus actividades y las corporaciones urbanas fueron el mejor espacio para la realización de sus expectativas (Pastor, 2004, p. 235). Así lo confirma Herrero Sánchez, quien indica que los ligures recurrían a mecanismos de protección corporativa como una forma de salvaguardar sus intereses y mantener su identidad colectiva (2007, p. 43). Su interés no se limitaba al comercio en la península y los puertos alrededor del Mediterráneo, sino que deseaban llegar a las Indias. Los mercaderes genoveses constituyeron el mayor grupo extranjero con cartas de naturaleza, lo cual les permitía participar en el comercio colonial. Brilli indica que si a los naturalizados se adicionan los genoveses nacidos en Cádiz (jenízaros), el número de habilitados para la carrera de Indias durante el siglo XVIII ascendía a 116 mercaderes (2013, pp. 229-230).

Uno de estos era don Carlos Malagamba, de quien se sabe que comerciaba con Lima entre 1788-1794. Malagamba era dueño de la fragata La Galga, con la que realizó viajes hacia Honduras (Alfonso Mola, 1992) y obtuvo su carta de naturaleza en 1785 (Brilli, 2008). Otro ligur gaditano, don Juan Bautista Rapallo, en 1796 envió a Lima canela y medias de diversas clases valorizadas en 35 mil pesos y con el producto 
de las ventas embarcó con destino a Cádiz cacao y cascari1la. ${ }^{8}$ También encontramos la casa de comercio Pedemonte y Ardizone, representada por don Juan Bautista Pedemonte y don Thomas Eustaqui Ardizone (Brilli, 2008). Ellos, con sus representantes en Lima, mantenían transacciones con el gobernador de Chile y próximo virrey del Perú, don Ambrosio O'Higgins, ${ }^{9}$ y con comerciantes limeños, como Juan Antonio Blaque, don Juan Antonio Ximeno, don Joaquín Bousa Varela y don Cesáreo Agustín de la Torre Ceballos; incluso a través de Ximeno tenían negocios con las familias De Comin, De Tagle, De Sos ${ }^{10}$ y Tamarria y Panizo. ${ }^{11}$

Pero también existían aquellos que no tenían licencia y surcaban los controles de la Casa de Contratación. Es el caso de don Francisco Vasallo (Basalo), quien en 1752 fue solicitado por la Real Hacienda y Cabildo Limeño a pedido de esta institución por haber pasado a territorios americanos sin licencia. En la captura de sus bienes se identificaron tres facturas: la primera por 44,622 pesos, la segunda por 33.929 pesos y la tercera por 8,222 pesos. Diversos consignatarios fueron llamados a presentar la respectiva mercancía o beneficios favorables a Vasallo. Los interesados indicaron que Vasallo no se encontraba en la capital y el proceso fue seguido por uno de sus más cercanos apoderados, don Alfonso Losada. ${ }^{12}$ Años

8 John Carter Brown Library, Colección Americana (jcbperu, b5850297; "Copiado de cartas de España que da principio en 30 de abril de 1792 y finaliza en 26 de abril de 1796").

9 Con O'Higgins mantendrá un largo pleito que data de la década de 1790. Ver: Archivo Histórico Nacional (en adelante AHN), Consejos, 21318, exp.1.

10 AHN, Consejos, 20272, exp. 2.

11 John Carter Brown Library, Colección Americana (jcbperu).

12 AGN, H-3, leg. 10, exp. 2; 1752. 
más tarde, Vasallo se vio involucrado en el proceso de expulsión de extranjeros seguido por el Consulado Limeño. ${ }^{13}$

\section{Negocios de los genoveses en la Ciudad de Los Reyes}

Los genoveses no solo llegaban como polizontes o ejecutores de oficios mecánicos. ${ }^{14}$ Existió también una migración de grupos familiares como los hermanos Antonio, Manuel y Pedro de Andrade; ${ }^{15}$ Pedro y Miguel Dinegro; Santiago y Cayetano Ferrer; Agustín y Juan Bautista Pelufo; y los hermanos Bacarreza. Estos últimos fueron un claro ejemplo de la contraparte de los polizontes. Antonio Bacarreza se estableció en Lima hacia 1769 y era conocido como relojero y bachiller de artesano. Comerciaba con géneros de Castilla, además de

13 AGN, GO-RE 1, leg. 14, exp. 258. Lima; 1763.

14 En el siglo xviII, el término "mecánico" hacía referencia a los oficios bajos de la república, como zapatero, herrero y otros, y comprendía todos los trabajos que se ejecutaban con las manos (RAE 1780: 614). Agrega el Diccionario de autoridades que lo mecánico se consideraba una cosa baja, soez e indecorosa (RAE 1783: 627). Estos oficios viles o mecánicos se basaban en la tradición y la costumbre y se accedía a ellos a través del sistema gremial de aprendizaje.

15 Los hermanos Andrade compraron una huerta en la calle de la Huaquilla, donde cada uno levantó viviendas y negocios. Solo Manuel y Antonio trabajaron estas tierras, ya que ambos compraron por partes iguales lo que le correspondía a Pedro. Manuel se dedicó a sembrar árboles frutales y construyó su casa y tres tiendas, incluso arrendó el callejón continuo al Monasterio de Santa Catalina, donde levantó habitaciones (AGN, Protocolos Notariales, Francisco Luque. Lima; 1778). Por su parte, Antonio María indicaba que el terrero de la huerta fue comprado hacia 1725 y que él fue quien inicialmente realizó la compra. Levantó casa y dos tiendas accesorias, además sembró una huerta. También era propietario de una pulpería y bodega en la calle de las Mantas, anexa a la Plaza Mayor, que compró al Monasterio del Carmen (AGN, Protocolos Notariales, Andrés de Quintanilla. Lima; 1749). 
oro, plata y pedrería, y junto a sus hermanos abrió una oficina de abrillantar diamantes en 1771 (Patrucco Núñez, 2005, pp. 172-173). Por su parte, su hermano Ambrosio logró asimilarse como oficial voluntario del Regimiento Provincial de Dragones de $\operatorname{Lima}^{16}$ y en 1790, a los 43 ańos, solicitó licencia para seguir la profesión religiosa en la Orden de San Francisco. ${ }^{17}$ El otro hermano, Cayetano, ejerció el comercio a diferentes escalas y obtuvo el rango de oficial del Regimiento Provincial de Dragones de Lima; ${ }^{18}$ asimismo, fue mayordomo de la Hermandad de Nuestra Seńora de las Mercedes. ${ }^{19}$ Don Cayetano era propietario de una tienda de comercio en la calle de Bodegones, ${ }^{20}$ donde expendía diferentes géneros.

Entre 1760-1830 he identificado una muestra de 180 casos de genoveses residentes en la Ciudad de los Reyes. De ellos, un $51 \%$ hace referencia a su oficio (cuadro 1) y un $13 \%$ indica ejercer más de un oficio, como Manuel Gavino, que laboraba como maestro armero y comerciante; Luis Musante, que indicaba ser maquinista, escultor de hierro y pulpero; Antonio de los Ríos, que oficiaba de peluquero y regentaba un almacén; y también don Félix Conforto, maestro platero con tienda pública en la calle de Mercaderes y dedicado extraoficialmente a comerciar por el Cabo de Hornos. ${ }^{21}$

Sin embargo, en general, destacan los que indican ser comerciantes, con tienda conocida y giro más allá del comercio al

16 Archivo General de Simancas (en adelante AGS), SGU, 7283, 9; 1790.

17 AGS, SGU, 7096, 80; 1790.

18 SGU, leg. 7120, 23; 1792.

19 AGN, Cabildo, CA-AD-3, leg. 14, exp. 1729; 1818.

20 AGN, Protocolos Notariales, José Simeón Ayllón Salazar; 1830.

21 AGN, Superior Gobierno, GO-BI-1, leg. 29, exp. 184; 1759. 
menudeo o en zonas aledańas a la capital. Estos representan un $19.6 \%$ del total. De otro lado, se encuentran los comerciantes al menudeo, que suman un 16.3\%; y los pulperos, $13.0 \%$. También hubo genoveses con rangos militares (Bacarreza, Manzanero, Valega) y religiosos como Ambrosio Bacarreza y Andrés de Isla Badaraco, que no era tal, pero estaba ligado a la Inquisición, como familiar y alguacil mayor del Santo Oficio.

\section{Cuadro 1. Oficios ejercidos por los genoveses, Lima, 1760-1830}

\begin{tabular}{|l|c|c|}
\hline \multicolumn{1}{|c|}{ Oficio principal } & Cantidad & Porcentaje \\
\hline Comerciante & 18 & $19.6 \%$ \\
\hline Comercio al menudeo & 15 & $16.3 \%$ \\
\hline Pulpero, chinganero & 12 & $13.0 \%$ \\
\hline Fondero, cocinero, panadero & 9 & $9.8 \%$ \\
\hline Cafés & 9 & $9.8 \%$ \\
\hline Chocolatero & 8 & $8.7 \%$ \\
\hline Bodeguero, cajonero & 5 & $5.4 \%$ \\
\hline Chacarero & 5 & $5.4 \%$ \\
\hline Militar & 2 & $2.2 \%$ \\
\hline Otros & 9 & $9.8 \%$ \\
\hline Total & 92 & $100 \%$ \\
\hline
\end{tabular}

Fuente: AGN, Protocolos Notariales. Lima, siglos XVIII y XIX.

En el rubro de chocolatería encontramos a don Juan María Maza, con tienda pública en la ciudad. ${ }^{22}$ Juan Andrés, otro

$22 \mathrm{Al}$ momento de realizar su testamento, da un detalle pormenorizado de los trastes que se encontraban en su tienda de chocolatería: "29 piezas de 
genovés afincado en ella, tenía tienda de chocolatería en la calle Santa Polonia, se dedicaba también a la venta de insu$\operatorname{mos}^{23}$ y formó compañía con Juan Monasz en 1784 con la finalidad de labrar chocolate, siendo Huancavelica uno de sus mercados frecuentes. Otros ligures dedicados a este oficio fueron Juan Bonasi, ${ }^{24}$ Juan Monaci -con tienda en Cinco Esquinas-, ${ }^{25}$ Antonio Canenso y Juan Piamonte (Patrucco Núñez, 2005, pp. 176-180). En este oficio encontramos como maestros examinados y vinculados al gremio de chocolateros de la ciudad a Juan María Masa, Juan Masaferro y Santiago Carcaño. ${ }^{26}$

Otro de los oficios recurrentes entre los ligures era el de pulpero. Aquí encontramos a don Agustín de la Terola y Jordán (Agustín Jordán). En sus primeros años en las Indias, residió y ejerció como comerciante en la ciudad de Guayaquil, donde tenía un hijo natural. Se dedicaba a la venta de aguardiente, que compraba al conde del Valle Oselle. Asentó residencia en el puerto del Callao y era dueño de tres pulperías en el presidio y una en el pueblo de Bellavista. ${ }^{27}$ En el mismo oficio estaba Antonio María de Andrade, con su pulpería en la

barbero, dos morteros de madera, cinco piezas de moler cacao corriente, un escaparate con seis arrobas de chocolate poco más o menos, un mostrador, una mesa, ocho barras de plomo, nueve barras de chocolatero [...]"; entre sus bienes también figuraban tres esclavos. AGN, Protocolos Notariales, Juan de Castañeda. En 1775, existían en Lima quince chocolateros con ventas anuales que alcanzaban los 4,300 pesos (Quiroz 2008: 167).

23 AGN, Protocolos Notariales, Juan de Castañeda; 1792.

24 AGN, Protocolos Notariales, Silvestre de Mendoza; 1809.

25 AGN, Protocolos Notariales, Gerónimo de Villafuerte; 1820.

26 AGN, Protocolos Notariales, Andrés de Sandoval; 1790.

27 AGN, Protocolos Notariales, José de Bustinza; 1755. 
calle de las Mantas; ${ }^{28}$ Lucas Barbiere y Blanco, en la calle del Tigre; ${ }^{29}$ Esteban Canesi, que regentaba dos pulperías, una en la esquina de los Borricos y la otra en la esquina de Piti; ${ }^{30}$ Nicolás Caneto, cuya pulpería se encontraba a una cuadra del convento de San Joseph $;^{31}$ Luis Musante, en la esquina de Quintín y la calle Santo Domingo; ${ }^{32}$ Juan Manuel Morales, pulpero en la Pampa de Lara; Manuel Pérez de Córdova, en la esquina de Silva; y Tomás Ricario y Andrés Sofiat, en la calle del Estanquillo (Patrucco Núñez, 2005, pp. 194-199). Aquí también se incluye al chinganero Bartolomé Otón. ${ }^{33}$

En el rubro de las fondas, encontramos a don Francisco Rato regentando la fonda Caballo Blanco y un café en la calle de La Merced. ${ }^{34}$ Familiar político de Rato era Ángel Carmelino, quien se casó con la hermana de su mujer. Carmelino poseía una finca en la calle de la Pescadería, donde habilitó una fonda; además, en 1817 mantenía un pleito por la propiedad de una bodeguita. ${ }^{35}$ Bartolomé Guerci poseía una fonda-café en la esquina de las Ánimas y otra fonda en la calle de las Mantas; ${ }^{36}$ asimismo eran dueños de fondas: Antonio Rubí de Bordiguera, el cocinero y fondero Cayetano Ferrari ${ }^{37}$ y Juan Bautista Pelufo, cocinero, que regentaba una en la ca-

28 AGN, Protocolos Notariales, Andrés de Quintanilla; 1749.

29 AGN, Protocolos Notariales, Ignacio Ayllón Salazar; 1817.

30 AGN, Protocolos Notariales, Pedro F. Iglesias; 1848.

31 AGN, Protocolos Notariales, Pablo Saavedra; 1790.

32 AGN, Protocolos Notariales, Vicente García; 1826.

33 AGN, Protocolos Notariales, Julián Cubillas; 1822.

34 AGN, Protocolos Notariales, Ignacio Ayllón Salazar; 1817.

35 AGN, Protocolos Notariales, José Gutiérrez; 1816.

36 AGN, Protocolos Notariales, Gaspar Salazar; 1812.

37 AGN, Protocolos Notariales, Manuel Malarín; 1803. 
lle de Petateros. ${ }^{38}$ Asimismo, se incluyen en este rubro a los panaderos Lorenzo Malarín, José María Oneti con su panadería en la calle de Copacabana y Juan Sobrera en la calle de Cascajal. ${ }^{39}$

En el negocio de los cafés se ubicaban Jorge Moreto, con una cafetería en la calle de las Campanas, abajo del puente; ${ }^{40}$ Juan Baptista con otros socios, en la plazuela de San Agustín; Juan Badinis, en la calle San Agustín; y también los fonderos Bartolomé Guerci y Francisco Rato. El caso más emblemático en este rubro es el café del genovés Francisco Carabana y el milanés Francisco Serio, en la calle de Santo Domingo (del Correo Viejo) (Holguín Callo, 2013, p. 68).

Dedicados al comercio menor se encontraban varios almaceneros, dueños de tiendas pequeñas, bodegueros, cajoneros, tenderos, etc. Aquí encontramos a don Próspero Ambrosio, con tienda en la calle de Mercaderes, donde expendía ropa y efectos de Castilla. Ambrosio se había trasladado a Lima en la década de 1750, por la vía de Quito, donde residía su tío Ventura Ambrosi, dedicado al comercio. ${ }^{41}$ En 1756, viajó a Cádiz para trasladar mercancías y dio referencias de representantes en el puerto ${ }^{42}$ En los momentos de la expulsión, y al zarpar en el navío San Joseph, registró un caudal de alrededor de 30 mil pesos. ${ }^{43}$ También se dedicaron al comercio menor

38 AGI, Contratación, 5703, N 12 (citado por Patrucco 2005: 181).

39 AGN, Protocolos Notariales, Ignacio Ayllón Salazar; 1821.

40 AGN, Protocolos Notariales, Ignacio Ayllón Salazar; 1820.

41 AGN, Superior Gobierno, GO-RE-1, leg. 13, exp. 224.

42 AGN, Protocolos Notariales, Valentín Torres Preciado; 1756.

43 AGN, Protocolos Notariales, Francisco Luque; 1761. 
Francisco Ambrosio; ${ }^{44}$ Felipe Bianchi ${ }^{45}$ Juan Carsolino, bodeguero en la esquina de las Aldabas; ${ }^{46}$ José Mananego, quien regentaba almacén, tienda y cajón de Ribera; ${ }^{47}$ Antonio de los Ríos, que además de almacenero era peluquero; ${ }^{48}$ y Bartolomé Grillo, que vendía al menudeo. ${ }^{49}$

En este mismo oficio estaban Alberto Macagi, quien formó compañía con su paisano Bernardo Gallo y abrieron un almacén en la calle de Mercaderes. Macagi se asoció también con Agustín Loyzo para trasladar mercancías en el navío La Concepción..$^{50}$ Otro tendero era Esteban Patrón, quien abrió cajón en la calle de Palacio. ${ }^{51}$ Por su parte, Juan de Urrese (Orrezi) mantenía una partida de efectos de Castilla valorados en 565 pesos..$^{52}$ Estos tres personajes consignaban en sus testamentos ser solteros y sin hijos. Quizás su estado de trotamundos y las propias vicisitudes del giro de negocio que llevaron no les permitió asentar una sola residencia.

En el grupo de los grandes comerciantes genoveses, no solo se considera a aquellos que realizaron importantes transacciones comerciales y mantenían considerable caudal, sino también a quienes llevaban a cabo sus movimientos fuera de las fronteras del Virreinato peruano y estaban posicionados en las altas esferas de la sociedad limeña colonial. Así,

44 AGN, Protocolos Notariales, Gregorio Gonzales de Mendoza; 1814.

45 AGN, Protocolos Notariales, Juan José Morel de la Prada; 1808.

46 AGN, Protocolos Notariales, José Simeón Ayllón Salazar; 1833.

47 AGN, Protocolos Notariales, Ignacio Ayllón Salazar; 1822.

48 AGN, Protocolos Notariales, Miguel Andrade y Santos; 1724.

49 AGN, Protocolos Notariales, Hilario de Ávila; 1808.

50 AGN, Superior Gobierno, GO-RE-1, leg. 13, exp. 224; 1761.

51 AGN, Protocolos Notariales, José de Bustinza; 1760.

52 AGN, Protocolos Notariales, Salvador Gerónimo de Portalanza; 1779. 
tenemos a José Canevaro, natural del pueblo genovés de Zuali, quien arribó a Lima junto con su hermano Miguel. Aquí contrajo nupcias con doña Francisca Valega (hija del genovés Félix Valega), quien aportó alrededor de 1,200 pesos valorados en muebles de su uso y una criada. Por su parte, Canevaro era dueño de un capital que ascendía a 56,175 pesos, divididos en 41,675 pesos por el valor de las mercaderías fletadas en la barca sarda Temistocle, anclada en Río de Janeiro, y 14,500 pesos en facturas pendientes de cobrar que mantenía del comercio en Guayaquil. En 1838, sus bienes en Guayaquil y Lima ascendían aproximadamente a 76 mil pesos. Canevaro, al momento de testar, separó de sus bienes seis mil pesos para ser enviados a su madre, residente en Génova, y mil pesos para su hermana Gerónima, con el objetivo de que tomara estado. En una de sus cláusulas legaba diez mil pesos a doña Francisca Valega, siempre y cuando se mantuviera viuda y soltera.

Otro ejemplo es el de don Lorenzo Manzanero, natural de la villa de Porra en El Final, también en Génova, quien sirvió en la Compañía de Cargadores de España con el grado de distinguido, en 1775. En el Perú, formó parte del Batallón Provincial de Milicias de Infantería Española de Lima y se incorporó en 1784 con el grado de teniente; en 1786, alcanzó el grado de capitán. ${ }^{53}$ Por estos servicios se le adeudaban entre 5 y 6 mil pesos: "de habilitación que hice a los cien soldados que estaban a mi cargo acuartelados, dándoles camisas, zapatos, medias, plata y dos pagas de mi salario, como le consta al habilitado teniente don Francisco Concha”. ${ }^{54}$

53 AGS, SGU, 7283,7. Lima; 1790.

54 AGN, Protocolos Notariales, Ignacio Ayllón Salazar; 1835. 
Manzanero apareció en la lista de suscriptores del Mercurio Peruano del mes de febrero de 1791 y, en los momentos de ebullición independentista, otorgó un donativo de tres pesos y medio mensuales durante el periodo 1811-1817; y también cuatro pesos mensuales para la sustentación del ejército expedicionario de Chile hasta $1818 .{ }^{55}$ Ese año, cuando él tenía 43, solicitó en el cuerpo miliciano el grado de coronel, el cual le fue negado por encontrarse otros en espera de esta gracia. ${ }^{56}$ Manzanero mantuvo una diferencia con el Superior Gobierno, ya que su nombramiento había aparecido en la Guía de forasteros de Madrid y no en un documento ministerial, como la Gaceta. ${ }^{57}$

Como parte del patrimonio de Manzanero se contaban dos casas y tierras para sembrar en su pueblo natal. En Lima, abrió tienda en la calle de Mercaderes, ubicada en el primer portal, con un considerable comercio de géneros de Castilla. El local comprendía los dos primeros números del portal. Con relación a esta tienda, don Lorenzo emprendió una dura lucha contra el gremio de botoneros para desalojarlos de los portales, con el argumento de que obstaculizaban el paso de los compradores y la visión de su tienda desde los carruajes. ${ }^{58}$ Además, se dedicó al comercio de aguardiente ${ }^{59}$ y amplió el giro de su negocio a ciudades de la sierra, como Jauja y Huancavelica. ${ }^{60}$

55 AGS, SGU, 7283,1. Lima; 1788.

56 AGN, Superior Gobierno, GO-CO-2, leg. 212, exp. 4011; 1818.

57 AGN, Superior Gobierno, GO-CO-2, leg. 213, exp. 4025; 1818.

58 AGN, Cabildo, CA-GC-4, leg. 29, exp. 14. Lima; 1784.

59 AGN, Superior Gobierno, GO-BI-5, leg. 169, exp. 689. Lima; 1798.

60 AGN, Cabildo, CA-JO-1, leg. 114, exp. 1939, Lima 1787. 
La reputada imagen de Manzanero como comerciante y vecino de la ciudad lo llevó a ingresar al círculo de la nobleza limeña. En efecto, por algunos años vivió en la casa de la condesa de Monte Blanco, ganó su confianza y llegó a habilitar con efectos de Castilla a su hija doña Josefa Salazar y Gaviño. ${ }^{61}$ Asimismo, Manzanero representó a la condesa del Castillejo en la aclaración de una deuda que ascendía a 17 mil pesos. ${ }^{62}$ Sin embargo, en la década de 1810 se declaró en quiebra y se formó un concurso de acreedores sobre sus bienes en el Tribunal del Consulado. Manzanero tuvo como plazo dos años para sufragar sus deudas y puso a disposición sus bienes y dependencias activas, y entregó alrededor de 15 mil pesos procedentes de la venta de los efectos que poseía y la llave de la tienda de comercio en la calle de Mercaderes. ${ }^{63}$

Como se ve con los diversos ejemplos mencionados, los genoveses lograron desarrollarse en diversos rubros económicos y realizaron alianzas con sus propios paisanos y con otros comerciantes limeńos durante el Virreinato. La diversificación de sus negocios hizo posible que tuvieran éxito en cada una de sus compañías. Es verdad que algunos no llegaron a poseer bienes, pero lograron mantenerse vigentes en el comercio limeño.

\section{Naturalizaciones y comercio a gran escala}

Aunque los genoveses formaron parte de la monarquía hispánica y fueron posteriormente aliados de la Corona española, en la práctica seguían siendo considerados extranjeros. Hay

61 AGN, Superior Gobierno, GO-BI-5, leg. 174, exp. 900; 1804.

62 AGN, Cabildo, CA-AD-3, leg. 9, exp. 277; 1789.

63 AGN, GO-BI-5, leg. 182, exp. 1019; 1809. 
que recordar que desde 1596 solo los españoles podían pasar y comerciar con las Indias (antes de eso, solo los castellanos), mientras que legalmente los extranjeros podían pasar solo si obtenían la Carta Real de Naturalización. En el libro IX de la Recopilación de leyes de los reinos de las Indias, título 27 "De los extranjeros que pasan a las Indias, y su composición y naturaleza, que en ellas pueden adquirir para tratar y contratar", se dejaba muy claro que ningún extranjero podría pasar a las Indias si no "estuviese habilitado con naturaleza y licencia nuestra” (1943, pp. 11-16). Pero la naturalización no fue el único camino legal, también hubo apertura para examinar oficios y profesiones mecánicas mediante el examen de capacidad y prestación de fianza y la licencia individual como privilegio de algún beneficio para los territorios indianos. Como último recurso, se podía hacer la composición o pago de una cantidad por la obtención del permiso, lo que era conocido como composición de extranjeros (Ots Capdequi, 1993, pp. 20-22).

En Lima, hubo cuatro casos certificados que han dejado rastro de sus cartas de naturaleza: Félix Valega, Félix Conforto, Francisco Ventura Valiente y José Rodulfo, además, en proceso de conseguirlas estaba don Bartolomé Vela. Otros genoveses que dan cuenta de su reconocimiento como "naturales" han dejado rastros participando como miembros del Tribunal del Consulado Limeño. Así, ubicamos a don An-

84 drés Corsino, don Cayetano Bacarresa y don Francisco Ferrari, con derecho a voto en $1802 ; 6^{64}$ y en 1815 , como deudor de la contribución que harían los miembros del Consulado para la defensa del reino, a don Francisco Ambrosi. ${ }^{65}$

64 AGN, TC-GO2, leg. 6, exp. 165; 1802.

65 Biblioteca Nacional del Perú, Manuscritos, D6327; 1805. 
Aunque el expediente del caso de Bartolomé Vela está incompleto, muestra cómo era el proceso de naturalización. Vela llegó a Lima hacia 1807. Doce años después buscó acreditar su comportamiento, tratos y contratos en la ciudad y solicitó el levantamiento de declaraciones juradas de diversos individuos. Si bien esta información no está asociada a la solicitud de la carta de naturaleza, podría ser un primer paso. Sobre sí mismo, Vela declaraba:

Me he comportado con bastante honor, siempre decidido por la justa causa del Nto soberano Sr Dn Fernando VII, procurando trabajar en todo lo que la suerte me ha proporcionado haciéndome por esto acreedor a que los principales sujetos de esta benemérita ciudad hayan echo de mi persona un gran aprecio [...] jamás he faltado a los pactos con ellos [...] motivo por el cual me han franqueado sus intereses en toda su extensión. ${ }^{66}$

Fueron ocho los testigos que presentaron información sobre Vela. Una vez concluido el proceso, el expediente se presentó al Procurador General del Cabildo limeño, en el cual los testigos reforzaron la adhesión de Vela a la causa monárquica, así como su desprendimiento monetario para el sostenimiento de tropas. Entre la información que brindan en el mismo expediente se resalta lo siguiente:

[...] vecino de irreprensible conducta, es adicto a la justa causa de Nuestro Soberano, uno de los que ha contribuido con dinero para el sostenimiento de las tropas del Rey [...] se le ha franqueado todos los efectos de comercio terrestre y marítimo que ha necesitado [...] se ha acreditado de tal suerte que a cualquiera almacén o casa de comercio que llega se le franquea cuanto pide, porque al cumplimiento de

66 AGN, Protocolos Notariales, José María de la Rosa; 1819. 
sus plazos hace efectivos los pagos [...] tiene unos pingues créditos por la puntualidad [...].

Otro aspecto se refiere a quienes no debían comerciar ni residir en Indias sin licencia del rey. El Tribunal del Consulado limeño era el encargado de velar que los extranjeros no lo hicieran. Así, por ejemplo, en 1782 se recibió la solicitud de "un extranjero" de asentarse en la ciudad que indicaba:

[...] aunque extranjero ha calificado como persona de distinción y carácter y por información de testigos que jamás ha comerciado ni actualmente comercia en esta ciudad y que solamente se ha empleado en oficios útiles y necesarios a la república [la ley tit 27 lib 9 lo exceptúa por ello de la expulsión] [...] mientras no se mesclase de ninguna manera en tratos y contratos de comercio para que si fuese del superior agrado de VE se le podrá permitir al suplicante que resida en esta ciudad, con la calidad de que no comercie y que para naturalizarse en estos reinos como indica ocurra a la Real persona en su Real y Supremo Consejo de Indias con arreglo a lo dispuesto en las leyes 31,32 y 44 del propio libro y títulos citados [...]. ${ }^{67}$

En esta dirección encontramos a Francisco Ventura Valiente, quien llegó al Perú en 1768, habiendo comprado bienes raíces por más de 15 mil pesos. Ventura participó en la expedición contra los portugueses en 1776, a la que entró como voluntario, e hizo un donativo de 100 pesos. Años después, el 1 de septiembre de 1785, se le concedió carta de naturaleza (Morales Álvarez, 1980, p. 336).

Por su parte, Félix Valega en 1813 presentó documentos relativos a sus méritos y servicios a la Corona para hacerse

67 AGN, H-3, 1031. Libro de Informes del Real Consulado de Lima; marzo de 1782. 
acreedor a dicha carta de naturaleza espańola. ${ }^{68}$ Lo cual se le concedió, dado que, en 1818, Valega indicaba "estoy declarado por la real piedad de Su Majestad en la clase de espańol, con todos los goces y prerrogativas de tal y como si hubiese nacido en los reinos de Castilla" ${ }^{69}$ Con esta distinción podría acceder a los beneficios del Consulado y comerciar sin mayores restricciones. Ese año, ejerciendo su carta de naturalización, solicitó ser incluido en la matrícula de comerciantes habilitados que publicaba el Consulado.

Valega llegó a participar como elector en el Tribunal y de los libros de aduanas del Consulado se puede desprender el giro de su negocio, sobre todo el proveniente de la península, de donde importaba telas, miel en botijas, pitas y sombreros. En 1811 embarco desde la península mercancías valoradas en 45 mil reales de vellón en la fragata Candelaria; y 99,914 reales de vellón en la fragata Neptuno. En 1814 llegó a registrar facturas por 99,933 reales de vellón. Luego de la independencia, Valega apareció como prestamista del Estado y aportó 2,000 pesos en 1823, mientras que en 1839 prestó la suma de 7,750 pesos (Mazzeo de Vivó, 2006, pp. 67-68)..$^{70}$

Otro de los grandes comerciantes fue don José Rodulfo y Estela, natural de Calizano (marquesado de Final), quien indicaba haber sido "incorporado en la nación española por Real carta de naturaleza”. Residió por muchos años en Panamá, donde contrajo nupcias con dońa Josefa Olasugarre (de Casagarre). De este matrimonio tuvo dos hijos, Isabel y José.

68 AGN, Superior Gobierno, GO-BI-1, leg. 57, exp. 1135; 1813.

69 AGN, Consulado, TC-GO-2, leg. 6, exp. 180; 1818.

70 También se pueden encontrar referencias en Mazzeo de Vivó (2012, p. 261). 
Este último, en 1819, era colegial del Real Convictorio de San Carlos. ${ }^{71}$ En su testamento, Rodulfo declara tener una casa en Lima y una barraca en el puerto del Callao, la cual quizás le servía de almacén. También era uno de los cuatro propietarios de la fragata Reina de los Ángeles, que comerciaba desde Cádiz con puertos del Pacífico (Iquique, Callao, Guayaquil, Panamá, San Blas y California). El giro de sus negocios lo vinculaba al circuito marítimo del Pacífico y al circuito terrestre del Virreinato peruano. Mantenía negocios en la ciudad de Huamanga comerciando efectos de Castilla ${ }^{72}$ y otros negocios con el mineral de Yauricocha. ${ }^{73}$

Su mayor negocio era el de transportista con su fragata Reina de los Ángeles, que cubría la ruta entre Cádiz y puertos del Pacífico, sobre todo con California. Rodulfo y sus socios habían tomado el comercio con California debido a las exenciones arancelarias con que la Corona benefició esa ruta. Por ejemplo, en 1817, salió de Cádiz con rumbo a San Blas y California, transportando, junto con frutos y efectos de Castilla, tropas del regimiento de Burgos con destino al Callao. En su retorno a Cádiz, la fragata transportó cacao de Guayaquil. ${ }^{74}$ Ese año, en San Blas, la fragata fue confiscada para el transporte de tropas y pertrechos de guerra a los puertos de California y no pudo retornar a la península, razón por la cual perdió todo el cacao que aguardaba en el

88 puerto del norte. Este hecho llevó a la ruina los negocios de Rodulfo.

71 AGN, Protocolos Notariales, Ignacio Ayllón Salazar; 1819.

72 AGN, Tribunal del Consulado, TC-JU-1, leg. 187, exp. 666; 1812.

73 AGN, Superior Gobierno, GO-BI-5, leg. 172, exp. 872; 1802.

74 AGN, Superior Gobierno, GO-BI-2, leg. 91, exp. 741; 1820. 
Su presencia en el Consulado Limeño era reconocida por los miembros de este Tribunal, que indicó: "es respetado por notorio buen nombre y entre los comerciantes de crédito y honradez, con los mejores sentimiento y anhelos por el mejor éxito de la defensa de la monarquía española en ambos hemisferios". ${ }^{75} \mathrm{Su}$ disposición para los requerimientos de la Corona era notable y llegó a entregar alrededor de 1,700 pesos entre 1807 y 1812 "para la urgencia de nuestra amada patria y los auxilios de las tropas en el Alto Perú". El detalle de sus donativos es el siguiente:

- En 1807, para el auxilio de Buenos Aires: 200 pesos

- En 1808, para el auxilio de la madre patria o el Estado: 517 pesos

- En 1810, para el mismo fin: 200 pesos

- En 1812, para la manutención de cuatro hombres por un año en el ejército del Alto Perú: 768 pesos.

En 1818, los navieros más importantes del Virreinato fueron convocados por la Comisión de Armamento del Tribunal del Consulado para armar buques de guerra y auxiliar a los realistas del Río de la Plata. En ese momento, la fragata Reyna de los Ángeles fue una de las utilizadas para este fin, por lo cual el Consulado se comprometió a sufragar a sus dueños 3,600 pesos mensuales por el tiempo que se empleara la nave en este servicio. ${ }^{76}$ En esos años, Rodulfo solicitó auxilio a la Real Hacienda y requirió que se le amortice el dinero que le adeudaba debido a su estado de pobreza y ruina. La Real

75 AGN, Tribunal del Consulado, TC-GR-1, leg. 117, exp. 401; 1813.

76 AGN, Tribunal del Consulado, TC-GR-1, leg. 117, exp. 430; 1816. 
Hacienda emitió entonces una resolución que amparaba a Rodulfo con 9,000 pesos consignados en 18 vales reales. ${ }^{77}$

\section{Los genoveses y la ocupación de Lima. El caso de Antonio Sacio}

En los primeros días de julio de 1821, con la inminente pérdida de Lima, el virrey La Serna decidió abandonar la capital del Virreinato llevándose todo lo que podía ser útil a los "patriotas". El virrey no se preocupó por la gente que dejaba en la ciudad; los españoles y europeos que quedaban tenían claro que las fuerzas patriotas tomarían represalias contra ellos (Mazzeo de Vivó, 2005, pp. 178-179). Quienes pudieron, se embarcaron en navíos neutrales, ya fuera desde el Callao u otros puertos y apareció así la figura del "emigrado". Otros se quedarían refugiados en puntos identificados en la capital. Más adelante, quienes volvieron y lograron adherirse a la causa patriota de la nueva nación pudieron recuperar sus bienes.

A finales de 1821 y comienzos de 1822 la persecución contra sospechosos de realismo se fue acentuando. Aquellos identificados como "españoles", "peninsulares" o "realistas" eran despojados de sus bienes, expulsados o encarcelados, mien-

90 tras que los emigrados perdían la totalidad o una parte importante de sus bienes. Inicialmente, las medidas fueron dirigidas contra los solteros, pero luego se extendieron a todos aquellos que no podían probar su adhesión a la causa independentista. Para estos asuntos, en octubre de 1821 se creó

77 AGN, Tribunal del Consulado, TC-GO-3, leg. 19, exp. 984; 1818. 
el Juzgado de Secuestros, encargado de incautar los bienes de los realistas y emigrados (Rizo Patrón, 2001, pp. 416-417).

La presencia de extranjeros en las colonias americanas, sobre todo en momentos de la independencia, ha sido vista a partir de su vínculo con las ideas independentistas y su participación en los procesos libertadores; esto aparte de su actuación como comerciantes, marineros, funcionarios de la administración colonial, piratas, etc. Se olvida, pues, que muchos extranjeros estaban asentados en diversos territorios de la monarquía hispánica y que la coyuntura independentista modificó su vida cotidiana. Como indica Langue, el papel de los extranjeros amerita ser considerado en relación con esta, teniendo en cuenta que muchos acusados de realistas o independentistas poco tuvieron que ver con la expansión y promoción de ideas (2014, p. 8). Su papel en uno u otro bando dependió de los intereses que debían salvaguardar o mantener.

Los extranjeros estaban arraigados en las comunidades locales. Esto se demuestra a través de los matrimonios con mujeres locales, el asentamiento de negocios, la compra de propiedades y los ańos que vivieron en los territorios a donde emigraron. Tomando como ejemplo el caso de Buenos Aires y momentos del proceso independentista, Herzog indica que el avecindamiento de extranjeros se relacionó con una convicción política y que las denominaciones de "americano" o "europeo" en ese momento no fueron asignadas para identificar a quien nació en América, la península o Europa; incluso entre estos existían "los fieles a la causa" y "los realistas", de manera que quienes reconocían y prestaban juramento al nuevo gobierno, poco a poco fueron recuperando sus derechos como miembros de la comunidad (2008, pp. 251-255). 
Este punto está aclarado por don Juan de Anzardo -dueño de la cuarta parte de la fragata Galen-, quien se vio involucrado en el secuestro de bienes, como se muestra en el expediente que se seguía en Lima al emigrado don José Agustín de Lizaur. Anzardo indicaba:

[...] porque ni soy español que hubiere emigrado de este territorio en odio de la Independencia proclamada y contra quienes declaró el Supremo Gobierno la ocupación de sus bienes, ni aun cuando lo fuera he permanecido antes ni después de esa justificada providencia en país enemigo, sino que por el contrario residía al tiempo de la compra bajo el Pabellón de una nación neutral y en lo posterior en esta corte contra cuyos habitantes hispanos que subsisten conformes con el sistema loable de la regeneración política del Perú, nada se ha resuelto que perturbe el goce tranquilo de sus propiedades. Soy un extranjero adicto a la causa de América y los de mi clase han recibido protección y amparo del mismo Supremo Gobierno, vivo gustoso en el país y las providencias hasta aquí expedidas hacen la salvaguardia de mi persona e intereses $[\ldots] .^{78}$

El nuevo gobierno llevó a cabo una investigación entre todos los escribanos de la ciudad para confirmar quiénes habían huido y cómo dejaron sus propiedades, rentas, negocios, cuentas por cobrar, pleitos, etc. Los espańoles estaban sujetos al toque de queda y a realizar cuantiosas contribuciones $y$ en general los europeos que se quedaron pronto estuvieron sujetos a una abierta persecución (Anna, 2003, p. 242). Incluso antiguos vecinos, esclavos o competidores en negocios que habían comprobado su adhesión al nuevo régimen comenzaron a denunciar a "sospechosos realistas". Para ello, se mandaron a confeccionar censos de las propiedades de "españoles", "peninsulares", "europeos" o "sospechosos rea-

78 AGN, Juzgado de Secuestros, leg. 467, exp. 163; 1822. 
listas" que fugaron con el ejército español al castillo del Real Felipe o hacia España. En estos listados podemos identificar a genoveses que fueron involucrados en el secuestro de sus bienes. Un ejemplo de ello es la denuncia del limeño Ramón Geni, por "el juramento que he prestado cordialmente en defensa de la Patria y la amada libertad", al europeo don José Sacio que fugó con el ejército realista y dejó su almacén con ropa de Castilla en la calle de las Mantas ("contando con la esquina tres tiendas, tiene las puertas verdes y con dos candados"). Por su parte, los comisarios Rafael Doyharart y Francisco Olivera indicaron que en la fonda de las Ánimas, con el pretexto de tomar un trago, encontraron a don N. Gaspar Grifoni, clérigo (capellán de Marina) y al genovés Maximiliano Albaurini, comerciante, ambos residentes en los altos de la casa del genovés Félix Valega. Al ser preguntado Grifoni por el nuevo gobierno, este contestó: "Todos son unos zapateros y hambrientos que han venido con muchos deseos de plata". Con estas declaraciones fue considerado sospechoso y enemigo del nuevo régimen. ${ }^{79}$

Aunque genízaro, Juan Clímaco Guerci -hijo del genovés Bartolomé Guerci, con el rango de capitán de granaderos de la Concordia- huyó con su tropa al Callao. En ese momento mantenía la tienda-almacén de la calle Arzobispo y la fondacafé de las Ánimas en la calle de los Judíos y sus bienes quedaron a cargo del genovés don Francisco N. Otros genoveses que aparecen en la relación de procesos de secuestros son don Bernardo Patrón, don Cayetano Dilisi ${ }^{80}$ don Antonio Sacio y Cayetano Ferrari. Este último, aunque ya había muerto

79 AGN, Juzgado de Secuestros, leg, 466, exp. 79; 1821.

80 AGN, Juzgado de Secuestros, leg. 473, exp. 355; 1822. 
en la ocupación de Lima, mantenía bienes tasados en 8 mil pesos entre dinero corriente, alhajas, esclavos y utensilios y enseres de su fonda en la calle de Mercaderes. Su albacea, don José Ramírez, tuvo que huir de la ciudad, dejó la fonda cerrada y enviaba noticias al respecto a sus familiares en Cádiz con otro genovés, Cayetano Parodi. ${ }^{81}$

Uno de los casos más documentados que he podido identificar al investigar el Fondo de Secuestros es el de la familia de los Sacio, Poleo y Heredia. Si bien el interés es ver esta etapa a través de Antonio Sacio, no hay que olvidar que su familia política descendía del genovés don Bartolomé Poleo, quién llegó a Lima a finales del siglo XVIII. ${ }^{82}$ Este, en 1811 casó a su hija Gertrudis (de trece años) con don Juan Antonio María Sacio, joven comerciante genovés. ${ }^{83}$ Tres años después, en 1814, casó a su hija Juana con Alfonso Heredia; ${ }^{84}$ y en 1818, a Manuela con Francisco Antonio García. ${ }^{85}$ Es así que antes de 1820 había casado a sus tres hijas mayores y quedó soltera doña Toribia, quien años más tarde cerraría el círculo familiar, como se verá.

81 AGN, Juzgado de Secuestros, leg. 464, exp. 46; 1822.

82 En el expediente matrimonial con Toribia Poleo se indica que Sacio era vecino de Lima hacía 28 años, es decir, probablemente arribó a la capital del Virreinato hacia 1797.

83 Juan Antonio María Sacio, natural de Génova, hijo legítimo de don Nicolás Sacio y de doña María Magdalena Boraño (AGN, Protocolos Notariales, José Gutiérrez; 1822).

84 AAL, Libro de Matrimonios del Sagrario, libro 11. Don Alfonso Heredia, natural de Cartagena de Levante, mayor de 25 años.

85 AGN, Protocolos Notariales, Ignacio Ayllón Salazar, P. 36; 1821. Antonio García natural de Laisuela, parroquia de San Esteban en las montañas de Santander, hijo legítimo de don Antonio García y doña María Antonia Martínez (AAL, Libro de Matrimonios del Sagrario, libro 11). 
En cuanto al repartimiento de dotes, la de dońa Juana ascendió a 11,889 pesos. No se ha encontrado el capital aportado por Heredia a la empresa conyugal, pero al momento de la muerte de Poleo, los 5 mil pesos que adeudaba fueron sumados a la herencia de doña Juana, además del valor de los muebles y menaje de la casa Mantequería. Alfonso Heredia quedó entonces como curador de los bienes de la pequeña de los Poleo, doña Toribia. Las tres hermanas al casarse recibieron como valor de dote la misma cantidad de dinero. En el caso de dońa Manuela, esta incluía el cajón de Ribera N. ${ }^{\circ}$, piezas de plata labrada, alhajas propias del uso y muebles ${ }^{86}$ mientras que la fortuna de su marido don Antonio García, al momento de contraer nupcias, ascendía a 30 mil pesos; ${ }^{87}$ en 1821, el matrimonio y sus hijos partieron a la península y dejaron como apoderado a su concuñado Antonio Sacio.

El matrimonio Heredia-Poleo se vio afectado con el secuestro de sus bienes. Heredia poseía los cajones de Ribera N. ${ }^{\circ} 5$ y 6, que venían de la testamentaría de don Bartolomé Poleo; uno de ellos lo tenía en companía con Francisco Llorens, español emigrado en el Callao, que buscaba embarcarse hacia la península y finalmente huyó con Canterac (al realizarse el balance de las mercancías cada uno obtenía alrededor de 10 mil pesos). Otra de sus propiedades era el café del Puente. Para resguardar los cajones de Ribera, Heredia realizó ventas ficticias con Sacio. Luego, la familia probó que los orígenes de estos cajones estaban en la testamentaría de don Bartolomé y que eran parte de la dote de dońa Toribia Poleo, quien estaba bajo la curaduría de Heredia. En efecto, doña Juana

86 AGN, Protocolos Notariales, Ignacio Ayllón Salazar; 1817.

87 AGN, Protocolos Notariales, Ignacio Ayllón Salazar; 1821. 
Poleo presentó documentos que acreditaban dicha repartición y logró que no fueran sujetos a investigación y se levantó la orden de secuestro de tales bienes. ${ }^{88}$

Por su lado, Sacio recibió de dote alrededor de 13 mil pesos, incluidos los 5 mil que adeudaba a don Bartolomé. En 1822, dio cuenta de que el aporte de Gertrudis Poleo, su primera mujer, ascendía aproximadamente a 24 mil pesos (11 mil adicionales a la dote). Entre sus propiedades, Sacio declaró cuatro cajones de Ribera (dos grandes, N. ${ }^{\circ} 10$ y 11 , y dos pequeños, N. 1 y 2), además de las bodegas de la calle Aldabas, Mantas y portal de Botoneros, adicionalmente de las alquiladas en las calles Pescadería y Santo Toribio. Entre 1812 y 1822 , sus movimientos financieros sumaron alrededor de 23 mil pesos entre pagos, ventas y alquileres. Sacio, en sus primeros años de comercio se dedicó a la compra-venta de aguardiente del valle de Ica; entre 1817 y 1818 invirtió cerca de 7 mil pesos en este género. ${ }^{89}$ También incursionó en 1822 en el eje Lima-Janeiro ${ }^{90}$ y anotó mantener 9,450 pesos en efectivo en Londres, con su apoderado Joaquín Ruiz de Alcedo. ${ }^{91} \mathrm{Al}$ morir su esposa, Gertrudis, contrajo matrimonio con dońa Juana Moreno Tejada, ${ }^{92}$ quien murió en 1825.

88 AGN, Juzgado de Secuestros, leg. 467, exp. 117; 1821.

89 AGN, Protocolos Notariales, Ignacio Ayllón Salazar; 1817-1818.

90 AGN, Protocolos Notariales, Ignacio Ayllón Salazar; 1822.

91 AGN, Protocolos Notariales, Ignacio Ayllón Salazar, P. 40; 1825.

92 AAL, Actas Matrimoniales, libro 11. Hija de don Nicolás Moreno y de Josefa Tejada. Fueron testigos de la boda: don Manuel Carrocella y don Martín Murillos. El expediente matrimonial indica que este enlace se llevó a cabo el 11 de diciembre de 1820, pero doña Gertrudis Poleo testó en octubre de 1821. Aquí queda comprobar algún error en uno de los dos documentos. 
En el contexto del secuestro de bienes de los emigrados, se identificaron otras propiedades de Sacio, quien las había transferido a otros para proteger sus intereses. Así, en el Juzgado de Secuestros se abrieron expedientes sobre la pulpería de la esquina de Correo Viejo y unos cajones de Ribera; ${ }^{33}$ por ejemplo, el cajón de Ribera N. 3 estaba a cargo de Manuel Calderón, español que emigró con las huestes realistas. ${ }^{94}$ También fue puesta a disposición del juzgado una pulpería en la esquina de Aldabas, administrada por don Manuel Domínguez, quien emigró al Callao. En cuanto a los cajones de Ribera N. ${ }^{\circ} 10$ y 11, los entregó "al partir" con don Domingo Barrasa. ${ }^{95}$ Esta fue la etapa más dura para Sacio, ya que fue perseguido por ser considerado español. Él indica sobre esta etapa:

[...] con las ocurrencias de la presente guerra, trastornos que se han experimentado y principalmente por las persecuciones que me hicieron considerándoseme por español como es notorio [...] no tuve adelantamiento alguno, sino antes menoscabos, quedando sujeto [...] a las pérdidas y quiebras de mis deudores [...] sin embargo los quebrantos notorios que sufrí en aquella época en el tiempo anterior a la entrada del ejército libertador en el puerto de Pisco [van pasando] [...] y debe esperarse cesen con los felices acontecimientos de las batallas de Junín y Ayacucho en favor de nuestras tropas $\left[\ldots . .{ }^{96}\right.$

93 AGN, Juzgado de Secuestros, leg. 470, hoja 48; 1821.

94 AGN, Juzgado de Secuestros, leg. 463, exp. 17; 1822.

95 AGN, Juzgado de Secuestros, leg. 471, exp 169; 1822.

96 AGN, Protocolos Notariales, Ignacio Ayllón Salazar; 1825. 
En 1825, Sacio declaró que había recibido 4 mil pesos en efectivo de "mi hermana política", dońa Toribia Poleo, sin gravamen ni registro de resguardo. Es en este momento cuando Sacio deja abierta la posibilidad de contraer terceras nupcias "por la necesidad en que me hallo de la crianza, educación y abrigo de mis hijos que se hallan todos en menor edad". La tasación de su capital en ese año ascendió a 162,885 pesos entre créditos activos y pasivos. En agosto de 1825 Sacio contrajo nupcias con doña Toribia Poleo, su "hermana política" y quien le había ayudado a restablecer sus bienes y posiblemente a cuidar de sus hijos. La dote de dońa Toribia será de aproximadamente 16 mil pesos divididos en: "13,669 pesos por el derecho de llave de los dos cajones de Ribera N. ${ }^{\circ} 5$ y $6.1,651$ pesos en alhajas de su uso y 780 pesos del valor de tres esclavos". ${ }^{97}$

Sacio se presentó como "vecino honrado y obediente a las órdenes de este Superior Gobierno"98 y buscó rescatar algunas de sus propiedades que aún se encontraban incautadas. Al mismo tiempo, mantuvo su giro comercial con varias plazas, sobre todo el vitivinícola y la venta de aguardiente. En defensa de sus intereses en este rubro y sobre la situación del país, hacia 1827 indicó:

[...] el único giro que hacemos los del país o no nos proporciona ventaja alguna. La agricultura se halla en el último grado de abatimiento. Las cosechas apenas son la cuarta

97 AAL, Expedientes Matrimoniales, № 12, julio de 1825. El expediente matrimonial se abrió a los tres meses de haber enviudado Sacio de su segunda esposa. Se piden las dispensas necesarias por la relación familiar que une a los esponsales y Sacio remarcó la necesidad de volverse a casar por la crianza de sus hijos y para afianzar su fortuna.

98 AGN, Juzgado de Secuestros, leg. 471, exp. 169; 1821. 
parte de las que antes se recogía [...]. Toda producción del país es libre y no adeuda derechos: los aguardientes son únicamente gravados. Yo no alcanzo la razón. Si se trata de aumentar el valor de las producciones nacionales por medio de la libertad de derechos, en igual caso están los licores [...] considere VE cuál es el gravamen que se impone al cosechero [frente] al Extranjero [...]. ${ }^{99}$

Estas líneas nos hacen ver a Sacio totalmente involucrado en la actividad comercial de la nueva República e identificado como vecino y ciudadano del país. Finalmente, mantener sus intereses comerciales lo llevó a adecuarse a la nueva corriente política e ideológica. Sacio murió hacia 1845-1846 y en la repartición de sus bienes retornó a doña Toribia el entero de su dote, además de partes gananciales, por lo que recibió alrededor de 37 mil pesos. Además, el matrimonio había adquirido la hacienda de Montecispe en Pisco (lo que confirma su interés en el negocio del aguardiente). Dońa Toribia ejerció de albacea de su marido junto a su sobrino-hijastro don Pablo Sacio y nombró como su albacea a don Juan Antonio García Poleo (su sobrino, hijo de su hermana Manuela), a quien casó con su hija doña Justa Sacio. ${ }^{100}$ Y lo mismo hizo con el hijo mayor de Sacio, don Pablo, casándolo con doña Felipa Heredia (hija de su hermana Juana y de quien este fue su curador) ${ }^{101}$, cerrando así la endogamia familiar.

\section{Conclusiones}

Como se ha descrito, los genoveses constituyeron una colonia muy activa dentro de la sociedad limeña, no solo por el

99 AGN, P-L 7-264.

100 AAL, Sagrario, Libro de Matrimonios; 1844.

101 AAL, Sagrario, Libro de Matrimonios; 1842. 
volumen de su población, sino por las redes de comercio que lograron entramar. Si bien su incursión en la ciudad de Lima está asociada a la figura del polizonte o desertor, los casos citados dan cuenta de que esta pudo ser una forma primitiva de ingreso de un grupo muy marcado, que tuvo como contraposición el asentamiento en la ciudad de ligures con trayectoria en otros espacios de la monarquía. De esta manera, a través de sus redes de paisanaje y amicales algunos de ellos pudieron participar de todo el circuito del Pacífico y transatlántico, y conformaron un grupo importante que evolucionó del pequeño tendero al gran comerciante con diversidad de negocios. Es importante estudiarlos para conocer sus estrategias de posicionamiento en el competitivo mercado limeńo, así como su convivencia y asentamiento formal en la ciudad, lo que les permitió participar en las corporaciones coloniales. Luego, entrada la emancipación los genoveses buscaron recolocarse y mantener el estatus que habían logrado adquirir.

Recibido: 10 de junio de 2017

Aprobado: 08 de mayo de 2018

\section{Archivos consultados}

Archivo Arzobispal de Lima (AAL)

Archivo General de Indias, Sevilla (AGI)

Archivo General de la Nación, Lima (AGN)

Archivo General de Simancas (AGS)

Archivo Histórico Nacional, Madrid (AHN)

Biblioteca Nacional del Perú, Lima

John Carter Brown Library, Rhode Island 


\section{Bibliografía}

Alfonso Mola, M.

(1992) Armadores canarios en Cádiz durante el periodo del libre comercio. En $X$ Coloquio de Historia CanarioAmericano (t. I, pp. 368-401). Las Palmas de Gran Canaria: Cabildo Insular de Gran Canaria.

Anna, T. E.

(2003) La caída del gobierno español en el Perú. El dilema de la independencia. Lima: IEP.

Brilli, C.

(2008) Genoese Merchants in the Eighteenth-century Spanish Imperial Trade. The Central Role of Gaditan Institutions. Recuperado de http://www.um.es/ixcongresoaehe/pdfB8/genoese.pdf

Brilli, C.

(2010) Mercaderes genoveses en el Cádiz del siglo XVIII. Crisis y reajuste de una simbiosis secular. En A. Crespo Solana, Comunidades transnacionales. Colonias de mercaderes extranjeros en el mundo atlántico (15001830) (pp. 83-102). Madrid: Doce Calle.

Brilli, C.

(2011) Il Rio de la Plata, nuova frontera del comercio ligure (1750-1810). En M.

Herrero Sánchez, Y. Ben Yessef Garfia, C. Bitossi y D. Puncuh (Coords.),

Génova y la monarquía hispánica (1528-1713) (pp. 933-964). Génova: Società Ligure di Storia Patria.

Brilli, C.

(2013) La importancia de hacerse español: La élite mercantil genovesa en Cádiz del siglo XVIII. En M. I. Lobato Franco y J. M. Oliva Melgar (Coords.), El sistema comercial español en la economía mundial (siglos XVII- 
XVIII): Homenaje a Jesús Aguado de los Reyes (pp. 225-255). Huelva: Universidad de Huelva.

Bustos Rodríguez, M.

(2005) Cádiz en el sistema atlántico. La ciudad, sus comerciantes y la actividad mercantil (1650-1830). Cádiz: UCA-Silex.

Campbell, León. G.

(1972) The Foreigners in Peruvian Society during the Eighteenth Century. Revista de Historia de América, Instituto Panamericano de Geografía e Historia (7374):153-163.

Herrero Sánchez, M.

(2007) La finanza genovese e il sistema imperiale spagnolo. Revista di Storia Finanziaria (19): 27-60.

Herzog, T.

(2008) Nosotros y ellos: españoles, americanos y extranjeros en Buenos Aires a finales de la época colonial. En J. Fortea y J. E. Gelabert. Ciudades en conflicto (siglos XVI-XVIII) (pp. 241-257). Valladolid: Junta de Castilla y León, Consejería de Cultura y Turismo, Marcial Pons.

Holguín Callo, O.

(2013) Cafés y fondas y Lima ilustrada y romántica. Lima: Universidad San Martín de Porres.

102 Langue, $\mathrm{F}$. (2014)

Extranjeros y revolución, ¿un binomio subversivo en la era de las independencias iberoamericanas? $\mathrm{Na}$ veg@merica, Revista electrónica editada por la Asociación Española de Americanistas (13). Recuperado de http://revistas.um.es/navegamerica/article/viewFile/208521/166761 
Mazzeo de Vivó, C.

(2005) El miedo a la revolución de la independencia del Perú, 1818-1824. En: C. Rosas Lauro, El miedo en el Perú, siglos XVI al XX (pp. 167-184). Lima: Sidea, PUCP.

Mazzeo de Vivó, C.

(2006) Los comerciantes, el consulado y los préstamos al gobierno republicano (Lima-Perú, 1820-1840). Revista Complutense de Historia de América, 32: pp. 63-84.

Mazzeo de Vivó, C.

(2012) Gremios mercantiles en las guerras de Independencia. Perú y México en la transición de la Colonia a la República, 1740-1840. Lima: IEP, BCR.

Morales Álvarez, J. M.

(1980) Los extranjeros con carta de naturaleza de las Indias, durante la segunda mitad del siglo XVIII. Caracas: Academia Nacional de la Historia.

O'Phelan, S.

(2005)

2005. Una doble inserción. Los irlandeses bajo los Borbones: del puerto de Cádiz al Perú. En S. O’Phelan Godoy C. Salazar-Soler (Eds.). Passeurs, mediadores culturales y agentes de la primera globalización en el mundo ibérico (pp. 411-440). Lima: IRA, IFEA.

Ots Capdequi, J. M.

(1993) El Estado español en las Indias. México: FCE.

Pastor, M.

(2004) Cuerpos sociales, cuerpos sacrificiales. México: UNAM, FCE.

Patrucco Núñez, S.

(2005) Italianos en la Lima borbónica (1700-1800). Su presencia e inserción en la sociedad virreinal. Tesis para 
optar el grado de maestría en Historia. Pontificia Universidad Católica del Perú, Lima.

Quiroz, F.

(2008) Artesanos y manufactureros en Lima colonial. Lima: BCRP, IEP.

Real Academia Española

(1780) Diccionario de la Real Academia Española. Madrid: RAE.

Real Academia Española

(1783) Diccionario de autoridades de la Real Academia Española. Madrid: RAE.

Recopilación de leyes de los reynos de las Indias mandadas a imprimir y publicar por la magestad católica del rey don Carlos II Nuestro Señor (1943) Madrid: Consejo de la Hispanidad. vol. 3, libro IX, título XXVII, ley I.

Rizo Patrón Boylan, P.

(2001) La emigración de los súbditos realistas del Perú hacia España durante la crisis de la independencia. En S. O'Phelan Godoy, La independencia del Perú. De los Borbones a Bolivar (pp. 416-417). Lima: PUCPBIRA. 